\section{Release of Chinese Cabbage Lines Derived from Recurrent Selection for Resistance to Soft Rot Disease}

\author{
Jianping Ren ${ }^{1}$ and Michael H. Dickson \\ Department of Horticultural Sciences, New York State Agricultural Experiment \\ Station, Cornell University, Geneva, NY 14456-0462
}

Additional index words. bacterial soft rot, Brassica rapa, disease resistance, Erwinia carotovora, recurrent selection

Yield and market quality of Chinese cabbage (Brassica rapa subsp. Pekinensis L.) are seriously affected by soft rot disease caused by Erwinia carotovora subsp. carotovora. Control of this disease is difficult because of host susceptibility and lack of effective bactericides. Researchers have been looking for resistance within the species or from related species (Asian Vegetable Research and Development Center, 1990; Nishi et al., 1970; Ren et al., 2000, 2001a; Shimizu et al., 1962, 1964), but no reliable, resistant sources have

Received for publication 24 Apr. 2000. Accepted for publication 8 Dec. 2000. This work was partly supported by Sakata Seed America, Inc. We thank the USDA-ARS, Plant Genetic Resources Unit; and the Institute of Vegetables and Flowers, Chinese Academy of Agricultural Sciences, for kindly providing the $B$. rapa germplasm used in this study. The cost of publishing this paper was defrayed in part by the payment of page charges. Under postal regulations, this paper therefore must be hereby marked advertisement solely to indicate this fact.

${ }^{1}$ Current address: PanAmerican Seed Co., 1S 861 Green Rd., Elburn, IL 60119. E-mail address: jren@panamseed.com been found or developed. Resistance to soft rot disease appears to be a quantitative trait controlled by multiple additive genes (Nishi et al., 1970; Ren et al., 2001b; Yamagishi et al., 1990). Here, we introduce four Chinese cabbage breeding lines (C3-26, C3-27, C3-28, and C3-29) derived from three cycles of recurrent selection that are more resistant than the original parents.

\section{Origin}

The initial population (cycle-0) consisted of the best 23 accessions of vegetable $B$. rapa of 300 evaluated for resistance to soft rot disease (Ren et al., 2001b). Most of the germplasm was obtained from the U.S. Dept. of Agriculture-Agriculture Research Service, Plant Genetic Resources Unit, Geneva, N.Y.; and the Institute of Vegetables and Flowers, Beijing. Information on PI numbers, subspecies names, and disease severity ratings are listed in Ren (1998). Recurrent selection was performed as described in Ren et al. (2001b) (Fig. 1). In each cycle, 18 plants from each line Chinese Academy of Agricultural Sciences, (defined as the progeny from a cross) were evaluated using a mist-chamber seedling inoculation method (Ren et al., 2001a), in which a needle was dipped into bacterial colonies and pricked into two leaf-petioles of 3-weekold seedlings. Inoculated seedlings were placed in a mist-chamber $\left(23{ }^{\circ} \mathrm{C}\right.$ and $\left.100 \% \mathrm{RH}\right)$ and rated after 24 to $36 \mathrm{~h}$ based on a rating scale of 1 to $9(1=$ no disease, $9=$ plant dead $)$. The most resistant plants were selected from the 20 most resistant lines [the lowest mean disease severity rating (MDSR) and highest percentage of plant survival]. Three or four selected plants from each selected line were crossed with plants from four other lines (partial-diallel crosses) by bud pollination. Some crosses were omitted because of variation in blooming periods. Following evaluation and selection of the progeny, additional cycles of crosses were made until three cycles were completed. About 69 to 77 crosses were made in each cycle. Detailed information on all crosses mentioned above is given in Ren (1998).

\section{Description}

C3-26, C3-27, C3-28, and C3-29 are the four cycle-3 lines released. The plants grow vigorously, form upright, barrel-shaped heads with leaves that curve inward without overlapping at the top, and are 45 to $50 \mathrm{~cm}$ high and 35 to $40 \mathrm{~cm}$ wide, with dark-green wrapper leaves and yellow-green inner leaves. Plants are ready for harvest between 80 and $85 \mathrm{~d}$ after planting.

Four to six parental accessions were involved in each of these four particular lines (Table 1). The parental accessions probably contained different resistance genes with additive effects (Ren et al., 2001b), which were pyramided within the cycle- 3 lines by three generations of intercrossing and selection. During trials with four replications at the seedling stage, as described above, and at the

Cycle -0

Cycle - 1

Cycle-2

Cycle -3

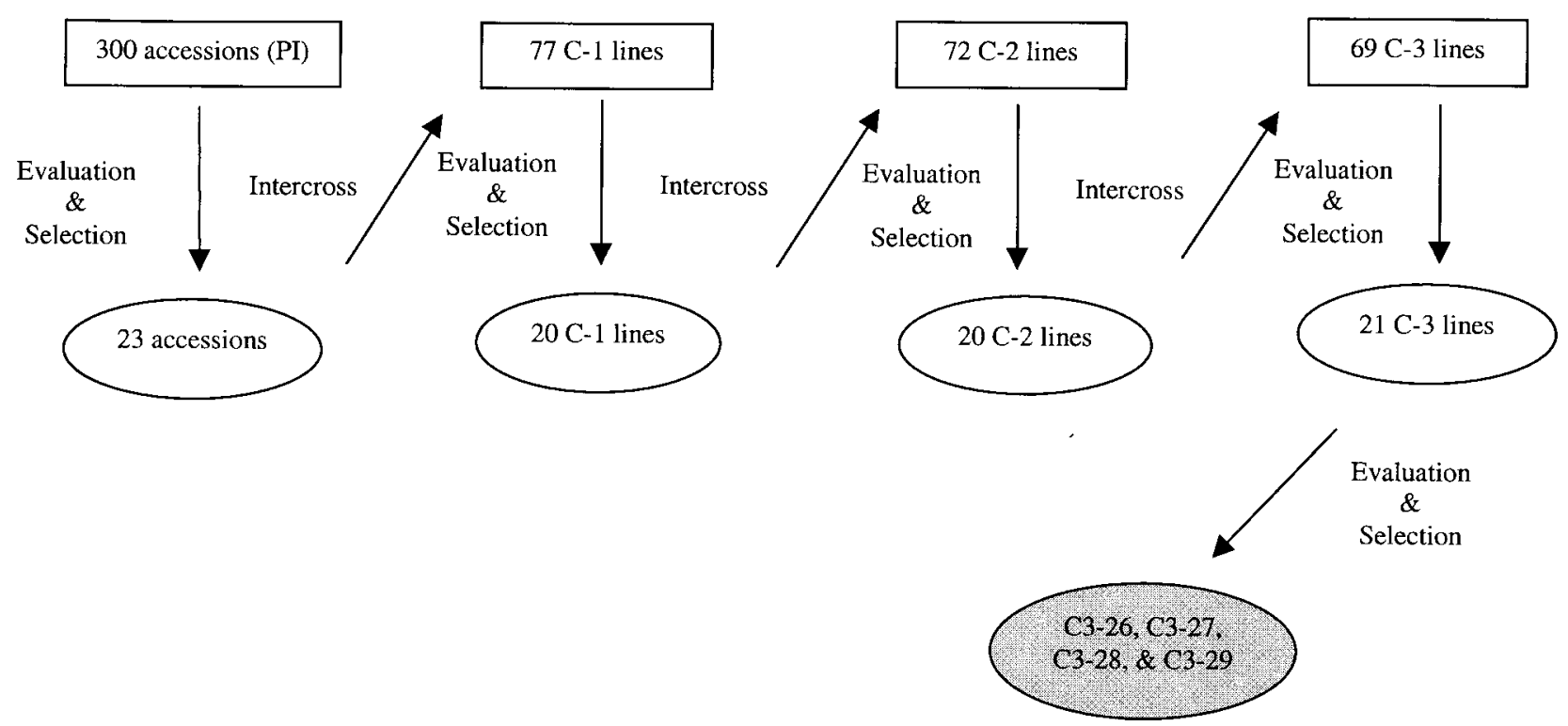

Fig. 1. Diagram of three cycles of recurrent selection of Chinese cabbage for resistance to soft rot disease. 
Table 1. Parental accessions and pedigree of four cycle-3 lines of Chinese cabbage derived from recurrent selection for resistance to soft rot disease.

\begin{tabular}{|c|c|c|c|}
\hline \multicolumn{4}{|c|}{ Cycle-3 } \\
\hline Accessions $^{\mathrm{z}}$ & Origin & lines & Pedigree \\
\hline$\overline{\mathrm{C} 2(2837)}$ & AVRDC $^{y}$ & C3-26 & $\begin{array}{l}\{[(\mathrm{C} 2 \times \mathrm{C} 3) \times(\mathrm{C} 4 \times \mathrm{C} 2)] \\
\times[(\mathrm{C} 9 \times \mathrm{C} 4) \times(\mathrm{C} 8 \times \mathrm{C} 3)]\}\end{array}$ \\
\hline C3 (G30444) & $---^{x}$ & & \\
\hline C4 (G30449) & --- & C3-27 & $\begin{array}{l}\{[(\mathrm{C} 13 \times \mathrm{C} 2) \times(\mathrm{C} 9 \times \mathrm{C} 4)] \\
\times[(\mathrm{C} 3 \times \mathrm{C} 2) \times(\mathrm{C} 5 \times \mathrm{C} 4)]\}\end{array}$ \\
\hline C5 (G30450) & --- & & \\
\hline C8 (PI508415) & Korea & C3-28 & $\begin{array}{l}\{[(\mathrm{C} 3 \times \mathrm{C} 2) \times(\mathrm{C} 5 \times \mathrm{C} 4)] \\
\times[(\mathrm{C} 9 \times \mathrm{C} 4) \times(\mathrm{C} 8 \times \mathrm{C} 3)]\}\end{array}$ \\
\hline C9 (G30786) & Japan & & \\
\hline C13 (G30451) & -- & C3-29 & $\begin{array}{l}\{[(\mathrm{C} 2 \times \mathrm{C} 3) \times(\mathrm{C} 5 \times \mathrm{C} 4)] \\
\times\{(\mathrm{C} 3 \times \mathrm{C} 2) \times(\mathrm{C} 4 \times \mathrm{C} 2)]\}\end{array}$ \\
\hline
\end{tabular}

${ }^{2}$ Accessions (except 2837 from AVRDC) were obtained from the USDAARS, Plant Genetic Resources Unit, Geneva, N.Y.

${ }^{y}$ AVRDC: Asian Vegetable Research and Development Center, P.O. Box 42, Shanhua, Tainan 74199, Taiwan.

${ }^{x}$ Accessions with unknown origin.

heading stage in the field, the cycle-3 lines showed better resistance than the parental accessions (Table 2). Field plants were inoculated by dipping a sharpened wooden dowel in an agar slurry of bacteria and forcing the dowel twice horizontally through the centers of the plants. Inoculated plants were overhead-irrigated for $7 \mathrm{~min}$ three times daily. Individual plants were rated $10 \mathrm{~d}$ later based on a 1-9 scale (where $1=$ no disease, $9=$ whole plant rotten). Field data presented in Table 2 are from the first replication only because of severe club-root infection in some plots.

\section{Performance}

Mist-chamberassays. In 1995, the average MDSR of the cycle-3 lines was significantly reduced from 5.7 (parental lines) to 4.0 , and average survival was increased from $72 \%$ to $89 \%$ at $23{ }^{\circ} \mathrm{C}$ and $100 \%$ RH. In a more severe test at $28^{\circ} \mathrm{C}$ and $100 \%$ RH in 1996 , the average MDSR of the cycle-3 lines was again significantly reduced from 6.5 to 3.1 , and the average survival was increased from $63 \%$ to $99 \%$. The susceptible control CC25 had a MDSR of 7.3 to 7.6 and only $30 \%$ to $45 \%$ of the plants survived. Resistance of the cycle- 3 lines and the parental accessions at seedling stage is compared in Fig. 2.

Field assays. Data from field trials also indicated improved resistance in the cycle- 3 lines. The average MDSR was reduced from 4.2 to 1.9 in the 1996 trial and from 5.9 to 3.9 in the 1997 trial. Resistance of C3-28 at early heading stage is compared with that of G30449 in Fig. 3.

\section{Availability}

Seeds of C3-26, C3-27, C3-28, C3-29, and their self-progeny can be obtained from Dr. Phillip Griffiths, Dept. of Horticultural Sciences, New York State Agricultural Experiment Station, Geneva, NY 14456-0462.

\section{Literature Cited}

Asian Vegetable Research and Development Center. 1990. Evaluation of soft rot on Chinese cabbage in the field and studies on isolation and
Table 2. Mean disease severity ratings of parental accessions of Chinese cabbage and the selected cycle-3 lines following inoculation with soft rot bacteria.

\begin{tabular}{|c|c|c|c|c|c|c|}
\hline & \multicolumn{4}{|c|}{ Mist-chamber seedling evaluation } & \multirow{2}{*}{\multicolumn{2}{|c|}{$\begin{array}{c}\text { Field evaluation } \\
\text { MDSR }\end{array}$}} \\
\hline & \multicolumn{2}{|c|}{$\mathrm{MDSR}^{\mathrm{z}}$} & \multicolumn{2}{|c|}{ Plant survival $(\%)$} & & \\
\hline & 1995 & 1996 & 1995 & 1996 & 1996 & 1997 \\
\hline \multicolumn{7}{|l|}{ Parents } \\
\hline 2837 & 4.1 & 5.3 & 75.0 & 70.8 & --- & --- \\
\hline G30444 & 5.5 & 5.8 & 78.3 & 91.8 & $4.3 \pm 0.6$ & $4.1 \pm 0.7$ \\
\hline G30449 & 5.6 & 6.9 & 75.0 & 50.0 & $3.9 \pm 0.3$ & $6.8 \pm 0.3$ \\
\hline G30450 & 5.2 & 6.1 & 87.0 & 75.0 & --- & --- \\
\hline PI508415 & 6.4 & 7.7 & 70.8 & 29.2 & $5.1 \pm 0.5$ & $6.8 \pm 0.2$ \\
\hline G30786 & 6.5 & 7.2 & 58.3 & 54.2 & $4.3 \pm 0.3$ & --- \\
\hline G30451 & 6.3 & 6.7 & 58.7 & 70.8 & $3.6 \pm 0.6$ & --- \\
\hline Average & 5.7 & 6.5 & 71.9 & 63.1 & $4.2 \pm 0.5$ & $5.9 \pm 0.4$ \\
\hline \multicolumn{7}{|l|}{ C-3 lines } \\
\hline C3-26 & 3.8 & 3.0 & 91.7 & 100 & $2.1 \pm 0.3$ & --- \\
\hline C3-27 & 4.5 & 3.7 & 87.5 & 100 & $1.9 \pm 0.3$ & $3.3 \pm 0.7$ \\
\hline C3-28 & 3.8 & 2.7 & 95.8 & 100 & $2.0 \pm 0.4$ & $3.6 \pm 0.5$ \\
\hline C3-29 & 4.2 & 2.9 & 79.2 & 95.8 & $1.4 \pm 0.3$ & $4.9 \pm 0.7$ \\
\hline Average & 4.0 & 3.1 & 88.9 & 98.6 & $1.9 \pm 0.3$ & $3.9 \pm 0.7$ \\
\hline \multicolumn{7}{|l|}{$\begin{array}{l}\text { Susceptible } \\
\text { control }\end{array}$} \\
\hline $\mathrm{CC} 25$ & 7.3 & 7.6 & 45.7 & 30.6 & --- & --- \\
\hline $\operatorname{LSD}_{0.05^{y}}{ }^{\mathrm{y}}$ & 1.5 & 1.6 & 30.4 & 28.8 & --- & --- \\
\hline
\end{tabular}

${ }^{2}$ MDSR: Mean disease severity rating from 1 (no disease) to 9 (plant dead). 'Based on Fisher multiple comparison.
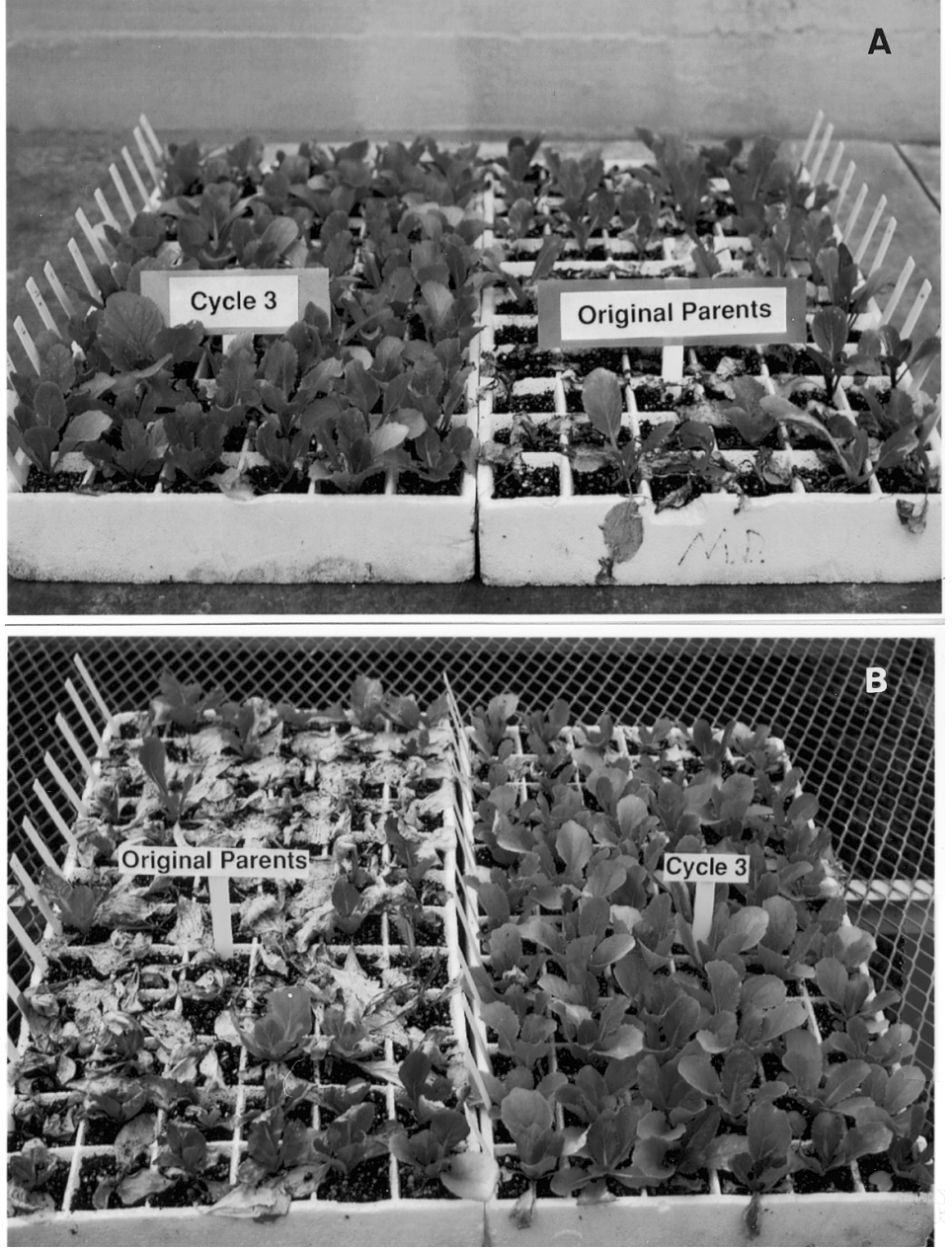

Fig. 2. Comparison of parental accessions and cycle-3 lines of Chinese cabbage in response to soft rot disease in 2 years of seedling evaluation in mist-chamber: (A) 1995 and (B) 1996. 

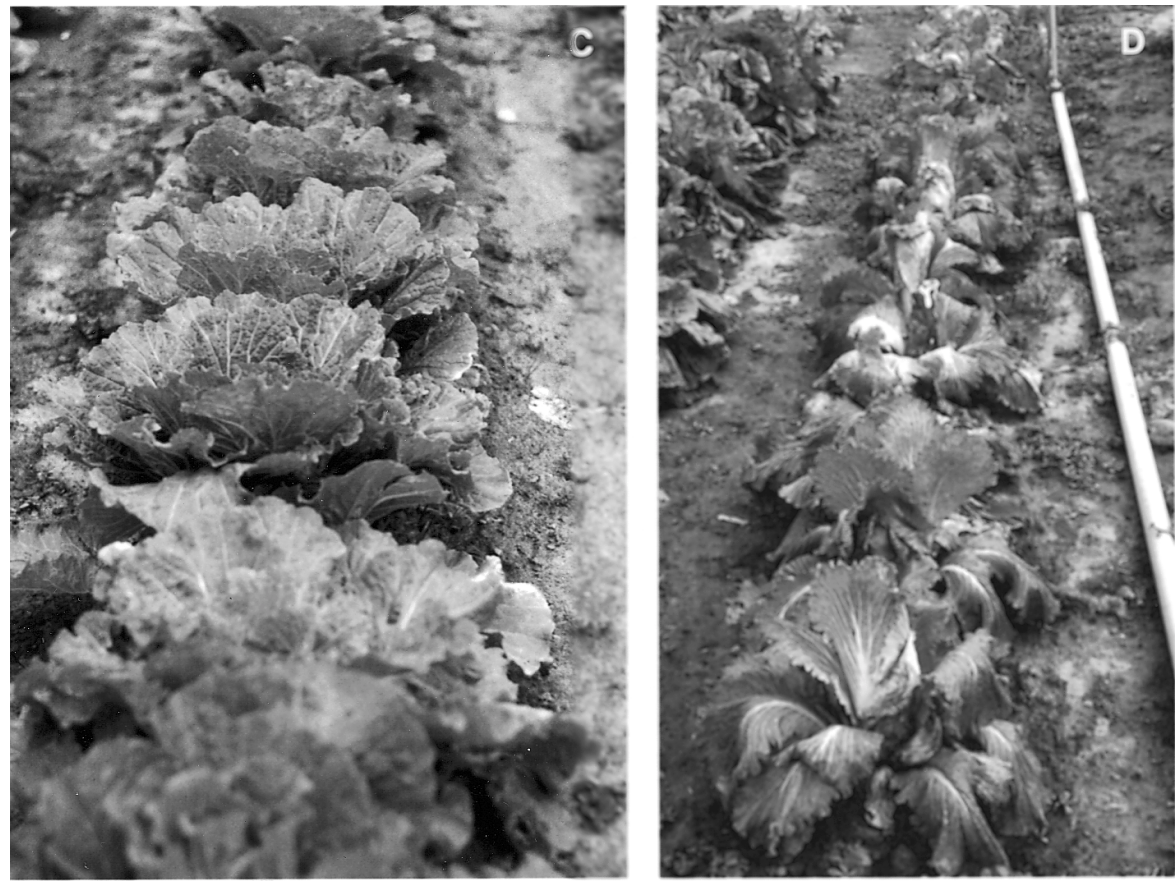

Fig. 3. Comparison of a parental accession and a cycle-3 line of Chinese cabbage in response to soft rot disease following inoculation in the field: (C) C3-28 and (D) G30449. quantification of Erwinia carotovora pv. carotovora, p. 28-32. In: Prog. Rpt. Asian Veg. Res. Dev. Ctr., Shanhua, Tainan, Taiwan.

Nishi, S., M. Toda, S. Umeda, and T. Toyoda. 1970. Studies on the breeding of Cruciferae vegetables by interspecific and intergeneric hybridization. II. Breeding of disease resistant Chinese cabbage by backcrossing to interspecific hybrids between cabbage and Chinese cabbage (in Japanese with English summary). Bul. Hort. Res. Sta. A9:101-128.

Ren, J.P. 1998. Resistance to bacterial soft rot (Erwinia carotovora subsp. carotovora) in Brassica rapa vegetables. PhD Diss., Dept. of Plant Breeding, Cornell Univ., Ithaca, N.Y.

Ren, J.P., M.H. Dickson, and E.D. Earle. 2000 Improving resistance to bacterial soft rot by protoplast fusion between $B$. rapa and $B$. oleracea. Theor. Appl. Genet. 100:810-819.

Ren, J.P., R. Petzoldt, and M.H. Dickson. 2001a. Screening and identification of resistance to bacterial soft rot in Brassica rapa. Euphytica 118:271-280.

Ren, J.P., R. Petzoldt, and M.H. Dickson. 2001b. Genetics and population improvement of resistance to bacterial soft rot in Chinese cabbage. Euphytica 117:197-207.

Shimizu, S., K. Kanazawa, and T. Kobayashi. 1962. Studies on the breeding of Chinese cabbage for resistance to soft rot. III. The breeding of the resistant variety 'Hiratsuka No. 1' by interspecific crossing (in Japanese with English summary). Bul. Hort. Res. Sta. A1:157-174.

Shimizu, S., K. Kanazawa, and T. Kobayashi. 1964. Studies on the breeding of Chinese cabbage for resistance to soft rot. IV. The artificial inoculation method for testing resistance to soft rot in Chinese cabbage (in Japanese with English summary). Bul. Hort. Res. Sta. A3:123-132.

Yamagishi, H., H. Yoshikawa, and S. Yui. 1990. Leaf morphology and soft rot resistance in offspring of a somatic hybrid between Chinese cabbage and kale (Cruciferae). Euphytica 47:215-221. 